\author{
Ренате Ратмайр \\ Экономический Унивеситет \\ (Вена, Австрия) \\ renate.rathmayr@wu.ac.at
}

\title{
МЕТАКОММУНИКАТИВНЫЕ РЕПЛИКИ В КОРПОРАТИВНОМ ОБЩЕНИИ: НА ПРИМЕРЕ ЖАНРОВ СОВЕЩАНИЙ И СОБЕСЕДОВАНИЙ
}

В статье рассматриваются метакоммуникативные реплики и единицы не в прескриптивных жанрах кодексов и учебников, а в аутентичной бизнес-коммуникации. Выбираются жанр совещания, в котором присутствуют как эгалитарная коммуникация на одном социальном уровне, так и коммуникация сверху вниз и наоборот снизу-вверх и жанр собеседования, в котором роли участников заранее фиксированы. Корпусом служит корпус совещаний и собеседований совместного проекта о дискурсивном анализе корпоративной коммуникации в России, описанный в книге «Корпоративная коммуникация в России. Дискурсивный анализ» [Милехина, Ратмайр 2017: 214, 259].

Цель статьи - показать, какова функция метакоммуникативных единиц и как они формулируются. Анализ показал, что в метакоммуникативных репликах употребляются самые разнообразные глаголы речи - такие, как говорить/сказать, отметить, переговорить, включать в коммуникачию, перечислить, определить, пробежсаться по пунктам и многие другие. Также употребляются метаязыковые формулы: скажем так, так сказать, как тебе сказать и др. На совещаниях они встречаются в основном в трех речевых актах - в директивных: кто что кому должен сказать, в ассертивных: кто кому что сказал и в коммиссивных: говорящий кому что скажет.

Тематический фокус на совещаниях - прямое или, реже, косвенное обсуждение тем, о которых предстоит говорить. Темы как правило задает ведущий, а в случае собрания представителей компании на одном уровне - все присутствующие. Кроме того, в директивных речевых актах распределяется, кто кому должен передать какие сообщения или поручения.

На собеседованиях интервьюер задает тему, о которой соискатель должен говорить на данном этапе собеседования. Встречаются также метаязыковые реплики, в которых формулируется побуждение говорить меньше, в более сжатой форме. 
В статье приводятся примеры из аутентичных записей совещаний и собеседований.

Ключевые слова: корпоративная коммуникация, метакоммуникативные единицы, организация диалога, повышение приемлемости, поддержка понимания

\section{1. Введение.}

Роман Якобсон [Якобсон 1975] различал шесть основных функций языка: коммуникативная (референтивная), апеллятивная, поэтическая, экспрессивная, фатическая, метаязыковая.

Метаязык (от греч. meta - после, за, позади) - язык, средствами которого исследуются и описываются свойства языка, называемого предметным, или объектным. Таким образом имеется назначение языка выступать одновременно в качестве средства (инструмента) исследования и в качестве средства (инструмента) описания языка. Метакоммуникация - зто «обычный вид общения, предметом которого является сам процесс общения» [Жукова, Лебедько, Прошина, Юзефович 2013: 245]. Условием успешной коммуникации считается постоянная рефлексия, постоянный контроль самого процесса общения участниками общения. И сама метакоммуникация отражает рефлектирование процесса общения, хотя рефлектирование может иметь и другие последствия, как, например, выбор другой формулировки, использование частиц, умалчивание определенных деталей и т.д. [Techtmeier 2001: 1450].

Темы метакоммуникации - самые разнообразные: всё, что на языковой поверхности общения и на фоне или заднем плане коммуникации играет роль для общения, может стать поводом метакоммуникативных высказываний, от ссылки на иллокутивный тип (Это было побуждение) и до распределения ролей (Теперь твоя очередь) [cp. Techtmeier 2001: 1453]. Hinrichs указывает на то, что в повседневной коммуникации избыток метакоммуникативных высказываеий может оказаться вредным, и приводит в качестве примеров жанры выяснение отношений, спор супругов, обмен репликами, упрек-оправдание и др. [Hinrichs 1991: 335].

Литературы о метакоммуникации много, а о метакоммуникации в деловом общении - мало. Интерес представляет, например, лингвистический анализ метакоммуникации внутри компаний [Meyer 2012]. Автора интересует, как сотрудники одной компании в Гэттинге (Германия) оценивают коммуникацию при введении новой системы менеджмента (окружающая среда, здоровье и безопасность). Эмпирический материал автора - это 20 качественных интервью с ведущими менеджерами высшего уровня, с одной стороны, и с сотрудниками, которые должны исполнить новые формы менеджмента, с другой стороны. Основной интерес исследования - какие лингвистические методы помогают оценить успешность и качество коммуникации внутри компании. Метакоммуникация в этой работе понимается на макроуровне текста и все высказывания респондентов в интервью рассматриваются как метакоммуникативные. Из результатов этого исследования 
можно отметить, например, наблюдение, согласно которому степень понимания, принятия (Akzeptanz) и выполнения стратегий менеджмента зависит от полноты объяснений и обоснований умышленности стратегий: если инструкции кажутся излишними, то они не воспринимаются [Meyer 2012: 242].

В нашей статье метакоммуникация рассматривается на микроуровне реплик и частей реплик. Цель статьи - показать, какие функции чаще всего выполняют метакоммункативные реплики и единицы в корпоративной коммуникации и как они формулируются. Для этого сначала представляются прагматические свойства (функции и особенности) метакоммуникативных единиц (MКЕ) ${ }^{1}$, описанные в лингвистической литературе. Затем будут представлены корпус и метод анализа. В следующих разделах приводятся примеры для основных функций МКЕ в текстах корпуса: организация диалога с помощью МКЕ, повышение приемлемости с помощью MКЕ и поддерживание понимания с помощью МКЕ.

\section{2. Прагматика (функции и особенности) метакоммуникативных единиц}

Содержание высказывания всегда охватывает не только лексические и грамматические значения, но и прагматические аспекты, такие как иллокуция, перлокуция, пресуппозиции, аллюзии и совокупность модальных значений, в том числе оценку достоверности утверждаемого факта. С целью повышения понимания высказывания на всех этих уровнях говорящие широко употребляют метакоммуникативные средства языка. Уточняют, например, иллокуцию: это обещание/ упрек/ побуждение и т. п. [cp. Bublitz 2001: 1334].

MКЕ отличаются в зависимости от коммуникативных ситуаций, они связаны с спецификой учреждений, в которых проходит общение, с ролями, которые выполняют участники [Techtmeier 2001: 1461], другими словами: кто (по статусу), кому, в какой ситуации, с какой целью говорит. В отличие от повседневной и особенно от фатической коммуникации деловая коммуникация почти всегда целенаправленна, она служит в общей сложности повышению прибыли данной компании [Cp. Riel, Cees B. M. van \& Charles J. Fombrun 2007]. В расслабленной межличностной коммуникации выбор слов и другие особенности оформления реплик менее существенны, менее «опасны», чем в официальном общении, например, на объединенных собраниях компаний. В корпоративной коммуникации особенно крупных компаний подробности формулировки речи даже регулируются в этических кодексах, например:

Правильная речь - это сочетание верного тона, артикулящии, произношения, громкости и точного подбора слов. [Корпоративные кодексы этики АКБ «Инвестторгбанк» (ОАО), ОАО «Социнвестбанк»; цит. по Скрипник 2012: 52]. Все рекомендации являются вариациями общего требования, сформулированного как констатация факта в одном из кодексов: Работник Компании независимо от уровня,

1 О разных названиях метакоммуникативных элементов речи см, например, Olszewska [2007: $11-13]$. 
вида и способа общения - вежлив, доброжелателен, отзывчив. [Русгидро, цит. по Рисинзон, Скрипник 2017: 354; о культуре речи в кодексах см.: Ратмайр, в печати]

В литературе приводятся разные названия функций метакоммуникативных единиц (МКЕ) в диалоге, которые можно собрать в три группы:

- поддержка понимания [Techtmeier 2001: 1453-1457), или интерпретационные функции, или функции по поддержанию взаимопонимания в диалоге [Голетиани 2013]: Ты имеешь в виду...?, Я имею ввиду, что.., то что я сейчас скажу, это объяснение моих предыдущих высказываний; Я знаю, что это нужно понять как совет.

Эти функции другими авторами интерпретируются как «комментирование, объяснение, констатирование, оценивание (как своих, так и чужих общений)» [ср. Жукова, Лебедько, Прошина, Юзефович 2013: 245];

- повышение приемлемости сказанного, редукция конфликтности, поддержка хороших отношений: То, что я сейчас скажу, не относится к теме, но...; Я знаю, что надо было бы начать доклад с выражения благодарности [Techtmeier 2001: 1453-1457]. Эта функция у Голетиани [Голетиани 2013] называется «модальная функция», например: Не могу согласиться...;

- организация диалога или полилога (диалогоуправление): Как мы поступим, сначала поговорим о проблеме $x$, а затем $y$ ?; Теперь говорю я; тут я сразу должен вмешаться, твоя критика ведь напрямую касается меня... [Techtmeier 2001: 1453-1457]. По Голетиани; диалогоуправляющие функции или функции по организации интеракции - это жанровые клише: открытие и закрытие интеракиии, введение нового топика, возвращение к предыдущему, сохранение, трансформация или закрытие топика [Голетиани 2013: 61].

Не всегда удается отнести МКЕ однозначно к какой-либо одной функции, что вызвано высокой степенью их полифункциональности. Она иногда приближает МКЕ к актам исправления, коррекции, например: Никто же не должен принимать это лично (persönlich nehmen; Bublitz 2001: 1458]. МКЕ Только маленькое дополнение к сказанному выше X-ом имеет не меньше следующих пяти функций: обоснование присвоения роли говорящего, маркировка прошедшего момента в дискуссии, частичное подтверждение высказывания X-a, критика высказывания X-a и смягчение критики и усиление приемлемости [Techtmeier 2001: 1457].

МКЕ могут быть инициативными или реактивными репликами, или частями реплик. Синтаксический состав может быть разный: полные предложения, подчиненные предложения, клишированные адвербиальные реплики [Techtmeier 2001: 459].

\section{3. Корпус и метод}

Примеры берутся из корпуса совещаний и собеседований совместного проекта о дискурсивном анализе корпоративной коммуникации в России [Милехина, Ратмайр 2017: 214 и 259-260] и из корпуса Р. Ратмайр «Русская речь и рынок» [Ратмайр 2013]. 
Корпус совещаний был записан Т. А. Милехиной в 2004-2014 гг. в различных российских компаниях в Москве, Санкт-Петербурге, Казани, Владикавказе, Саратове и других городах в присутствии и с разрешения руководства и сотрудников соответствующих компаний. «Материалы записывались в компаниях разного профиля деятельности: банковского и издательского бизнеса; электронной торговли; маркетинговых коммуникаций; производства отделочных материалов; производства и продажи мебели; лесозаготовки; торговли алкогольной продукцией и запчастями» [Милехина, Ратмайр 2017: 218].

Корпус собеседований содержит записи 26 собеседований. Материалы были собраны в первом полугодии 2008 г. и во втором полугодии 2012 г. в компаниях и кадровых агентствах Москвы и других городов России.

Применяемый метод - это функционально-прагматический и лингвистический дискурсивный анализ [Brünner 2009: 153 и сл.], который обеспечивает интерпретацию особенностей речевого поведения в социальном и общественном контексте.

Поиск частотных метакоммуникативных средств в корпусах охватил существительные и глаголы речи, глаголы понимать и значить, фразеологизм иметь в виду, синтагмы то есть, в смысле (ср. [Голетиани 2003: 339]).

\section{4. Организация диалога}

Для жанра совещаний характерна, с одной стороны, несимметричность ролей и важность статуса, а с другой неформальность: полилог присутствующих, когда говорят все одновременно и нейтральная тональность варьируется по целому спектру - от шутливой до грубой. Изменение тональности тесно связано с терпимым отношением к употреблению грубых слов и выражений, а также с конфликтностью обсуждаемых ситуаций. Грубость встречается очень редко, она в этом случае может быть связана и с лояльным отношением к ругательствам, которые воспринимаются как показатель дружеских, неформальных отношений в коллективе. При этом важную роль играет возраст участников (ср. [Милехина, Ратмайр 2017: 230-231]).

Совещания проводятся с определенной целью, и темы определяют, как правило, руководители. Употребляемые при этом метакоммуникативные средства Olszewska [2007: 36 и сл.] описывает как «тематизирующие метатекстемы». На совещание CB8-2012, записанном в торговой компании по электронике в Москве, обсуждаются проблемы, связанные с продажей. Прямое обсуждение темы имеет место в примере (1), косвенное в примере (2):

1. $<$ И Я не знаю/ что у нас там получится по пятнице и по субботе и воскресенью/ сейчас на эту тему поговорим/ но ситуация именно такая... // (CВ8-2012).

2. $\langle$ И> Чтобь нам в бесконечность в какую-то сейчас не уходить / я хотел на эту тему отдельно/ так сказать/ собраться / не в рамках оперативного собрания/ (CB8-2012).

В примерах (3) и (4) метакоммуникация выражается в конативном акте. Присутствует также проспективная и ретроспективная минимизация собственных 
вербальных, ментальных и других действий в интерпретациях речи и оправданиях (ассертивные речевые акты) с помощью частицы просто. А в примерах (5) и (6) руководитель распределяет обязанности и призывает к кооперативности:

3. $<\mathrm{A}>$ Этот вопрос я возьму на себя/ и решу его в ближайшие там два дня/ два/ три дня/ так вот//(СВ18-2012).

4. $<$ В. $>$ Антон/я просто поясню/ здесь дело в том что такая/ н-не неопределенность/ по этому проекту/ (ПРА).

5. С1 - Давайте скажем Ермакову/ чтобы уходил от/ них// (CВ 13)

6. $<\mathrm{B}>$ Ребята/ давайте не будем/ вернемся в конструктивное русло беседь и давайте определим задачи/ что мы хотим// (СВ18-2012).

Планирование речевой деятельности компаний - одна из основных целей совещаний. В примере (7), в репликах Макса хорошо видна полифункциональность MКЕ: говорится не только об организации речевой деятельности, но и оценивается информация как понятная, как конфиденциальная:

7. Макс. - Я в течении дня вам скажу/ угу/ вот// ну// вся информация/что обязательна/ можно сказать/ что вся информация/которая будет усльшиана мною/ она как бы понятна со стороны компании/которая в интересах компании/ она как бы конфиденциальна/ в следствие необходимости/могу подписать соответствуюшую бумажку// (СВ 21-2012); Макс. - Да/ но что хотел еще отметить/ что если какие-то будут там недочёты скажем там/какие-то у меня вопросы будут/ я буду сразу как бы эти все моменты включать в коммуникаиию/ скажем/ сразу сообщать что если/ по ходу дела мы будем сразу это устранять// (СВ 21-2012).

Есть совещания, которые почти целиком являются метатекстом. В примере (8), из записи совещания по рейтингу агентств маркетинговых коммуникаций, входящих в группу, обсуждается последовательность действий и оценка этого:

8. 1 - То есть с точки зрения мысли структурности очень хорошо/ Начинаем рейтинг объясняем почему мы вторые где наша роль куда мы идем/ дальше переходим к активу отвечаем на вопросы связные с конфликтом бизнеса по клиентам//

2 - Ну да и по людям//

1 - По людям/ Озвучиваем те моменты которые мы хотим озвучить//

2 - Ну вроде как я все старалась включить//

1 - По-моему очень хорошо// Давайте зафиксируем/ дождемся когда он вызовет//

2 - Ну в понедельник мы договорились ориентировочно потому что он говорит что-то «Погода Я отлежаться хочу»//

1 - Понятно// Ну хорочо/я бы даже сказала отлично/ (CВ 11-2012)

Пример (9), в котором спорят о том, кто что сказал, иллюстрирует высокую степень интертекстуальности: говорят о том, что было и будет сказано, просят чтото сказать. А в примере (10) объединены коммиссивный и директивный речевые акты:

9. мужской голос - Я только что сейчас рассказал/ что там// мужской голос Ну хорошо/ мы Валере скажем/ он поставит/ помоет// мужской голос - Оксана говорит/ чтобы здесь не было ничего там лишнего/что в лесу рассортируем всё/ 
и сразу повезем//; мужской голос - Я ничего не сказал/ я спрашиваю / сортировка будет в лесу или здесь?; мужской голос - Я и сказал/ вот это предложение сортировать в лесу//; Макс. (перебивая) - A/ вот еще последний момент / еще хотел/ в понедельник у нас с Евгением по плану еще / мы вот с Ларисой когда переговаривали (СВ 11-2012)

10. <A2.> Mbl просто-напросто должны уже говорить о каких-то конкретных вещуах/ говорить скажем о (нрзбр.) шансах/ (ПИК).

Анализ записей совещаний показал, что в метакоммуникативных репликах употребляются самые разнообразные глаголы речи, такие как говорить/сказать, отметить, переговорить, включать в коммуникацию, перечислить, определить, пробежаться по пунктам и многие другие. Также употребляются метаязыковые формулы: скажем так, так сказать, как тебе сказать и др. Они на совещаниях в основном встречаются в трех речевых актах — в директивных: кто что кому должен сказать, в ассертивных: кто кому что сказал и в коммиссивных: говорящий кому что скажет/сказал.

Гораздо реже, чем на совещаниях, диалогоуправляющие МКЕ употребляются в собеседованиях. Собеседования являются непубличным жанром устной корпоративной коммуникации на грани внутренней и внешней (полу-внутренняя корпоративная коммуникация): представитель компании, чаще всего менеджер по персоналу или сам руководитель компании должен отобрать наиболее подходящего нового сотрудника компании. Другой вариант, если отбор персонала организуется при помощи рекрутинговых агентств, тогда интервьюер - профессиональный рекрутер. Соответственно они имеют место либо в компании, либо в рекрутинговом агентстве, если функция подбора персонала частично выведена в аутсорсинг. Бывают и смежные формы, когда руководитель компании ведет собеседования в помещениях рекрутингового агентства, которое уже сделало предварительный отбор соискателей (например: СБ4-2008).

На собеседованиях интервьюер задает тему, о которой соискатель должен говорить на данном этапе собеседования, например, употребляя глаголы речи: neречислить, определить, сказать в побуждении, например, когда спрашивают о методах, которые соискатель собирается применять на курсах по повышению квалификации, или просит соискателя задавать свои вопросы, если они есть:

11. $<C>$ Как вы считаете/ чем должен заниматься менеджер по обучению и развитию персонала у нас в компании? Основные обязанности перечислите/ какие вы видите? [...10 строчек пропущено]

$<C>\ldots$ вот а какими методами вы бы... определили или что можете нам сказать о том что... (СБ3-2008).

Материал Корпуса, записанного в 2008 г., свидетельствует, что чаще всего требуется рассказать о причинах ухода с предыдущего места работы

12. <Э.> Ешё раз можете назвать причину увольнения?

$<$ К.5> Я же сказал что/ у нас немножко видение разошлось//

$<Э$.> Я поэтому говорю/ ещё раз напомните/ вот честно говоря забыл/ не записал сюда//(СБ4-2008) 
В записанном в 2012 г. в большом бизнес центре в Москве собеседовании (СБ10-2012) участвуют: $<$ AА $>30$ лет, менеджер по рекрутменту, крупной компании и $<$ ИС $>31$ год, кандидатка на вакансию. В начале обсуждается тематическая последовательность, причем в противоречии к обычному порядку кандидатка хочет ее определить сама.

13. $<$ АA > э-э поэтому я предлагаю нашу встречу по... построить таким образом/ ну э-э хотелось бы чтобы вы рассказали о себе в контексте вашего резюме/ может быть тех задач уже которые вы выполняли в качестве эйчар бизнес партнера/ да/ [4 строчки пропущено] <AA > . я с вашего позволения мм... буду задавать вам уточняюшие какие-то вопрось / $<$ ИС $>$ конечно/ да/ $<\mathrm{AA}>$ пере... перебивать вас/ вы там уж не сочтите меня таким... бестактным хамом/ <ИС> э-э конечно/ я наоборот даже может быть попросила бы вас акиентировать те моменты/ потому что в общемто опыт достаточно большой $<\mathrm{AA}>$ угу/ $<$ ИС $>$ несмотря на то что я не так долго в эйчаре/ $<\mathrm{AA}>$ угу/ $<$ ИС $>$ и поэтому может быть вы мне сакиентируете то что интересует вас/ вот ну как бы какой у вас таргет/какой у вас фокус/(СБ10-2012)

\section{5. Повышение приемлемости высказываний и реплик}

В отличие от организации диалога, которая относится к уровню содержания совещаний, приемлемость высказываний относится к уровню отношений между их участниками (cp. [Bublitz 2001: 1331]). Конструктивное, эффективное общение предполагает взаимное соблюдение постулата кооперации Грайса [Grice 1975]. Требуется минимизация конфликтности, принятие даже противоположных мнений или по крайней мере уважение к ним.

Интересно, что приемлемость, очевидно, важна в собеседованиях, а в совещаниях нужна в гораздо меньшей степени. Это вызвано скорее всего тем, что на совещаниях члены компаний знают друг друга, уровень отношений среди них урегулирован, а на собеседованиях уровня отношений «еще нет», зато есть явная необходимость создания взаимодоверия между еще не знакомыми персонажами. С этой целью употребляются, например, превентивные МКЕ. Один директор отдела кадров употребляет предварительное извинение извините за некорректность вопроса, но, как она сказала в интервью, конечно, спрашивает женских соискателей о планах рожать детей, поскольку это риск, конечно: $<C K>$ Hу а мы сразу спрашиваем// Вот я/ сразу/ спрашиваю говорю/ «Вы извините мне/м-м-м/некорректность моего вопроса»// (И36-2008).

Можно добавить, что потом в собеседованиях она применяла превентивные извинения непоследовательно. Не хочу Вас перебивать; не хочу Вам противоречить - другие превентивные метакоммуникативные реплики, характерные для корпоративной коммуникации. Говорящий с их помощью показывает, что он соблюдает правила вежливой коммуникации, но лишне не тратит времени. А ретроспективная метакоммуникативная минимизация собственных вербальных, ментальных и других действий выражается в интерпретациях речи и оправданиях (ассертивные речевые акты). 
В собеседованиях встречаются также метакоммуникативые реплики, в которых формулируется побуждение говорить меньше, в более жатой форме. Другими словами, призывают соискателей к соблюдению постулата количества Грайса [Grice 1975].

14. <M.> A-а/ на Менжинского / все/ вижу... (пауза) Давайте с вами начнем с региональной сети города $x$ / ну вкратие/ я думаю что по... этим местам наверно до... до фирмы х можно вкратие// (СБ 5-2008).

Требование соблюдения постулатов количества, релевантности и ясности также встречается в этических кодексах некоторых компаний: Сотрудник Банка обязан: предоставлять клиенту как можно более полную информацию о Банке и услугах, быть внимательным к потребностям клиента, стараться предложить те услуги, которые могут его заинтересовать; максимально удовлетворять запросы клиенma. [Корпоративный кодекс этики ООО КБ «Профит Банк», по Скрипник 2012: 44].

Ретроспективные МКЕ сигнализируют, например, о неловкости. В примере (15) метаязыковой формулой скажем так выражается неудобность при ответе на вопрос о сугубо личных отношениях соискателя. Интересно, что личные вопросы задаются не только женщинам, но и мужчинам. Так директор рекламной компании удивляется, что 37-летний соискатель еще не женат, и прямо спрашивает его:

15. <Э> А вы до сих пор холосты?

$<$ К 9> Я разведен скажем так. (СБ4-2008).

В рамках анализа переговоров и функций в этом жанре частицы просто встречались многие примеры, где частица сопровождает интерпретацию собственной речи и управление тем, как понимает эту речь адресат. Реализуются метакоммуникативные акты с глаголами речи в форме настоящего-будущего совершенного вида (я просто поясню, ну просто я сейчас скажу), реже в будущем времени несовершенного вида (просто буду отвечать) или в инфинитиве с настоящим временем модального глагола хотеть (просто хочу определиться), или же с формой прошедшего времени глагола хотеть, при сохранении отношения к будущему (я тебе просто хотел дорассказать). Частица смягчает категоричность речи говорящего (ср. [Ратмайр 2013: 180-185]).

\section{6. Поддержка понимания}

В корпусе обнаружено мало примеров, указывающих на поддержку понимания с помощью МКЕ. В примере (16) из собеседования женщина-интервьюер не уверена, правильно ли она поняла указания соискательницы, а в примере (17) организация диалога, точнее определение темы интервьюером, а соискатель подтверждает, что он понял директивный акт. Пояснение оборотом иметь в виду иллюстрирует пример (18):

16. $<K>$ А я правильно поняла что вы учились в у... $<$ ЕП> В РГГУ// $<K>A$-a/ это в РГГУ/ все/ поняла/ значит с другой стороны читала неправильно/ (смеется) $<$ ЕП> Да/ да-да-да/ (СБ 08-2012.).

17. $<$ ЕП> А... можно вот/ вы рассказываете про систему/ да/ бизнеса/ а вы конкретно вот что там делали/ вы открывали с нуля/ вы работали с новыми 
партнерами/ вы интернет строили/ что конкретно? <E> Ага/ понял/ значит изначально/ изначально я пришел как менеджер проекта (СБ 08-2012).

18. <ЕП> Ну это вот комфорт понимается как атмосфера/ потому что есть состояние комфорта в котором можно вообще ничего не делать/все равно тоже будет комфортно// $[<K>$ Да/ да... не/ я имею в виду все-таки профессиональный комфорт/ <EП> Ну-у/ безусловно конечно важна $<E>$ вот/ ну и опять же чтобь это гармонично сочеталось с моей жизнью/с личной я имею в виду/ (СБ 08-2012).

В корпусе есть пример объяснения значения экономического метода мотивации, который не служит кооперативной атмосфере собеседования, а, наоборот, выражает некоторую агрессивность соискательницы по отношению к интервьюеру. В уже цитированной беседе СБ10-2012, записанной в 2012 г. в большом бизнесцентре в Москве, участвуют: <АA> 30 лет, менеджер по рекрутменту, крупной компании и $<$ ИС $>31$ год, кандидатка на вакансию.

19. <ИС> я-я до этого интер... я вообще интересуюсь соичиникой/ я интересуюсь э-э методом мотивации по Герчикову/ я его очень много применяю/ <AA> немножко расскажите что это такое/ буквально... <ИС> э-э ну Герчиков просто наш российский ученый который разработал достаточно простой базис э-э мм... ну... там неких факторов которые разделяют $<A A>$ угу/ < ИС> мотивации на чеmыре э-э на четыре типа/ соответственно там/ ну те которым нужны награды/ те которых мотивируют деньги/ те кому нужна административная работа $<A A>$ угу/ <ИС> и как бы менеджерские функиии/ ну вот по вот такому базису в таблице еще э-э дополнительно есть у него некие люмпень $<A A>$ угу/ $<$ ИС $>$ коmорых вообще ничего не мотивирует/ (СБ10-2012).

\section{Резюме}

Метакоммуникация - существенный элемент любой коммуникации. На примере жанров «совещание» и «собеседование» было показано, что в разных жанрах корпоративного общения функции МКЕ различаются по частотности. В совещаниях очень важную роль играет организация диалога, обсуждение того, о чем будет идти разговор, кто должен сказать или сделать что-то. Наблюдается организация диалога на уровне темы, ролей говорящих и слушающих, распределение вербальных и других задач.

На собеседованиях как распределение ролей, так и тематические рамки заранее существуют и обсуждаются в меньшей степени (хотя в одном из приведенных выше примеров соискательница в какой-то степени взяла на себя роль ведущего и задавала темы беседы).

На уровне взаимоотношений партнеров по коммуникации действует повышение приемлемости высказываний, важным средством выражения которого также являются МКЕ. Применяются как превентивные, так и ретроспективные МКЕ, смягчающие возможную конфликтность интеракции. В рассмотренных жанрах встречаются также МКЕ, поддерживающие взаимопонимание, причины их сравнительно низкой частотности подлежат дальнейшим исследованиям. 


\section{Список литературы}

Голетиани Л. Коммуникативная неудача в диалоге. На материале русского и украинского языков. München: Verlag Otto Sagner, 2003.

Голетиани Л. Использование метакоммуникации в диалогах с намеренным нарушением коммуникативных постулатов. // Ритуал в языке и в коммуникаци/ отв. ред. Л. Л. Федорова, М.: Языки славянских культур, 2013. Стр. 57 и сл.

Жукова И.Н., Лебедько М.Г., Прошина З.Г., Юзефович Н.Г. Словарь терминов межкультурной коммуникации. М. : Флинта Наука, 2013. 632 с.

Милехина T. А., Ратмайр Р. (отв. ред.) Корпоративная коммуникация в России: дискурсивный анализ. Коллективная монография. М. : Языки славянской культуры, 2017. 632 с.

Ратмайр $P$. Культура речи в этических кодексах компаний и реальное общение на примере обслуживания клиентов // “Труды Института русского языка”, вып. 3. М., 2017. C. 115-125.

Рисинзон С.А., Скрипник Е. Кропоративные этические кодексы // Корпоративная коммуникация в России: дискурсивный анализ / отв. ред. Т. А. Милехина, Р. Ратмайр. М. : Языки Славянской культуры, 2017. С. 353-371.

Скрипник $E$. Эксплицитная коммуникационная политика в российских компаниях на примере корпоративных кодексов этики, Дипломная работа, Вена 2012.

Brünner $G$. Linguistische Diskursanalyse und ihre Anwendung auf die Wirtschaftskommunikation." // Diskurs und Ökonomie: Diskursanalytische Perspektiven auf Märkte und Organisationen, Rainer Diaz-Bone; Gertraude Krell, Wiesbaden: VS Verlag für Sozialwissenschaften, 2009, pp. 153-176.

Grice H.P. Logic and conversation. // Syntax and Semantics. Vol. 3: Speech Acts, Peter Cole; Jerry L. Morgan, New York: Academic Press, 1975. Pp. 41-58.

Bublitz W. Gesprächskonstitution III: Prozeduren // Text- und Gesprächslinguistik. Ein internationales Handbuch zeitgenössischer Forschung, Bd. 2, Berlin, New York 2001. Pp. 13310-1340.

Grice H.P. Logic and conversation. // Syntax and Semantics. Vol. 3: Speech Acts, Peter Cole; Jerry L. Morgan, New York: Academic Press. 1975. Pp. 41-58.

Hinrichs U. Linguistik des Hörens. Hörverstehen und Metakommunikation im Russischen. Wiesbaden: Harrassowitz, 1991. 385 Seiten.

Meyer M. Linguistische Analyse innerbetrieblicher Metakommunikation. Frankfurt/ Main: Peter Lang Verlag, 2012.

Olszewska D. Metatexteme in den Geisteswissenschaften. Typologie - Funktionalität-Stilistik. Gdansk: Wydawnictwo Universytetu Gdanskiego,. 2007, 323 S.

Riel, Cees B. M. van \& Charles J. Fombrun. Essentials of corporate communication: Implementing practices for effective reputation management. London \& New York: Routledge, 2007.

Techtmeier B. Form und Funktion von Metakommunikation im Gespräch// Text- und Gesprächslinguistik. Ein internationales Handbuch zeitgenössischer Forschung, Bd. 2, Berlin, New York 2001. Pp. 1449-1463. 
Электронный ресурс Якобсон, Р. Лингвистика и поэтика. www.philology.ru/ linguistics1/jakobson-75.htm Москва 1975 (3.2.2018).

\author{
Renate Rathmayr \\ Vienna University of Economics and Business \\ (Austria, Vienna) \\ renate.rathmayr@wu.ac.at
}

\title{
METACOMMUNICATIVE ELEMENTS IN BUSINESS COMMUNICATION: WITH EXAMPLES FROM BUSINESS MEETINGS AND JOB INTERVIEWS
}

In this article, we analyze metacommunicative elements in authentic business communication - not in prescriptive codices and manuals - with actual examples from business meetings and job interviews. In the latter the role of participants is predetermined, whereas in business meetings communication happens at different hierarchical levels. The corpus for this analysis is the same as in the Russian-Austrian joint project of discourse analysis of Russian Corporate communication [Milechina, Ratmajr 2017: 214, 259].

The aim of this paper is to show which functions particular metacommunicative elements fulfill and how they are formulated. Speakers use different verbs to express the act of speaking like for instance: talk, speak, mention, note, have a talk with someone, list, determine, discuss item by item. We also find metacommunicative formulas like for instance, let's put it this way, so to speak, how can I tell you. They occur in the meetings in three types of speech acts: in directive acts the speaker wants to commit the addressee to a particular verbal action, in assertive acts the speaker agrees to, or confirms, statements as being true or factual, and in commissive speech acts the speaker promises to commit himself to a particular verbal action.

The thematic focus in meetings is direct or, less frequently, indirect speech about the topics of the speech. Normally it is the leader, who decides the topics, but if all participants are of the same level, they all decide the topics together. In directive speech acts someone who has to perform informative speech acts or give orders to do something is appointed.

In job interviews, the interviewer determines the topics on which the interviewee is required to speak. In the corpus, we also found metacommunicative formulas in which the job applicant is asked to speak less or in a more concise way. In other words, the applicant is asked to apply Paul Grice's postulate of quantity. In the paper, one can find examples of all types of metacommunicative text fragments in authentic meetings and job-interviews.

Keywords: corporate communication, metacommunicative elements, organization of dialogue, increased acceptability, help for understanding. 


\section{References}

Brünner G. Linguistische Diskursanalyse und ihre Anwendung auf die Wirtschaftskommunikation." // Diskurs und Ökonomie: Diskursanalytische Perspektiven auf Märkte und Organisationen, Rainer Diaz-Bone; Gertraude Krell, Wiesbaden: VS Verlag für Sozialwissenschaften, 2009, pp. 153-176.

Goletiani, L. Kommunikativnaja neudacha $v$ dialoge. Na materiale russkogo i ukrainskogo jazykov. [Communicative failure in the dialogue. On the material of Russian and Ukrainian languages]. München: Otto Sagner 2003. (In Russ.)

Goletiani, $L$. [The use of meta-communication in dialogues with a deliberate violation of communicative postulates] // Ritual v jazyke i v kommunikacii / otv. Red. L. L. Fedoro$v a$ [Ritual in language and communication / ed. L. L. Fedorova], M.: Jazyki skavjanskich kul'tur, 57 ff. (In Russ.)

Grice, H.P. Logic and conversation // Syntax and Semantics. Vol. 3: Speech Acts, Peter Cole; Jerry L. Morgan, New York: Academic Press, 1975. Pp. 41-58.

Bublitz, W. Gesprächskonstitution III: Prozeduren // Text- und Gesprächslinguistik. Ein internationales Handbuch zeitgenössischer Forschung, Bd. 2, Berlin, New York 2001, 1310-1340.

Grice, H.P. Logic and conversation // Syntax and Semantics. Vol. 3: Speech Acts, Peter Cole; Jerry L. Morgan, New York: Academic Press, 1975. Pp. 41-58.

Hinrichs, $U$. Linguistik des Hörens. Hörverstehen und Metakommunikation im Russischen. Wiesbaden: Harrassowitz, 1991, 385 Seiten

Meyer M. Linguistische Analyse innerbetrieblicher Metakommunikation. Frankfurt/ Main: Peter Lang Verlag 2012.

Milechina, T.A., Ratmajr R. (ed.) Korporativnaja kommunikacija v Rossii: diskursivnyi analiz. [Corporate Communication in Russia: Discursive Analysis] Moscow, Jazyki slavjanskoj kul'tury Publ, 2017. 632 p. (In Russ.)

Olszewska, D. Metatexteme in den Geisteswissenschaften. Typologie - Funktionalität -Stilistik. Gdansk: Wydawnictwo Universytetu Gdanskiego. 2007, 323 S.

Ratmajr R. [Speech culture in the ethical codes of companies and real communication on the example of customer service] // „Trudy Instituta Russkogo jazyka. vol. 13“. Moscow, pp. 115-125. (In Russ.)

Riel, Cees B.M. van \& Charles J. Fombrun. Essentials of corporate communication: Implementing practices for effective reputation management. London \& New York: Routledge, 2007.

Risinzon S. A., Skripnik, E. [Corporate ethical codes] // Korporativnaja kommunikacija v Rossii. Diskursivnyi analiz / otv. red. T. A.Milechina, R. Ratmajr [Corporate Communication in Russia: Discursive Analysis / T. A. Milechina, R. Ratmajr eds.] Moscow, Jazyki Slavjansoj kul'tury Publ, 2017, pp. 353-371. (In Russ.)

Skripnik, E. Eksplicitnaja kommunikacionnaja politikamv rossijskich kompanijach na primere korporastivnych kodeksov etiki. Diplomnaja rabota [Explicit communication policy in Russian companies on the example of corporate codes of ethics. Graduation thesis]. Vena, 2012. 
Techtmeier, B. Form und Funktion von Metakommunikation im Gespräch// Text- und Gesprächslinguistik. Ein internationales Handbuch zeitgenössischer Forschung, Bd. 2, Berlin, New York 2001. Pp. 1449-1463.

Zhukova, I. N., Lebend'ko, M. G., Proshina Z. G., Juzefovich, N. G. Slovar' terminov mezhkul'turnoj kommunikacii. Moscow, Flinta Nauka Publ 2013

Электронный ресурс Jakobson, R. Lingvistika i poetika. www.philology.ru/linguistics1/jakobson-75.htm Moskva 1975 (3.2.2018). 